\title{
El nuevo paradigma del patrimonio y su consideración con los paisajes: Conceptos, métodos y prospectivas*
}

\author{
Rocío Silva Pérez \\ Víctor Fernández Salinas \\ Universidad de Sevilla. Departamento de Geografía Humana \\ rsilva@us.es \\ salinas@us.es
}

\section{Resumen}

Este artículo se adentra en el debate sobre el paisaje, el patrimonio y el territorio desde un entendimiento del patrimonio como asignación social e institucional de valores y desde la propia complejidad territorial y tipológica de los paisajes patrimoniales. Plantea un acercamiento conceptual y metodológico a tales paisajes centrado en los actores patrimoniales y en sus dinámicas apreciativas (los procesos de patrimonialización), así como en los elementos y argumentos en torno a los que se aglutina la identificación social e institucional con los paisajes (los vectores patrimoniales). Esboza una propuesta de traslación empírica que ejemplifica en paisajes de distintas dominantes y escalas, y concluye con una valoración crítica de los instrumentos utilizados en el reconocimiento patrimonial institucional y en la gestión de los paisajes, atendiendo a sus potencialidades y limitaciones.

Palabras clave: patrimonio; paisajes patrimoniales; vectores patrimoniales; procesos de patrimonialización; instrumentos de gestión

Resum. El nou paradigma del patrimoni i la seva consideració amb els paisatges: Conceptes, mètodes i prospectives

Aquest article s'endinsa en el debat sobre el paisatge, el patrimoni i el territori des d'una comprensió del patrimoni com una assignació de valor social i institucional i des de la complexitat territorial i tipològica dels paisatges patrimonials. El text proposa una aproximació conceptual i metodològica a aquests paisatges centrada en els actors econòmics i en les dinàmiques d'apreciació (els processos de patrimonialització), com també en els elements $\mathrm{i}$ arguments que catalitzen la identificació social i institucional amb els paisatges (vectors

* Este artículo se inserta en un programa de investigación sobre paisajes patrimoniales actualmente desarrollado por dos proyectos $\mathrm{I}+\mathrm{D}+\mathrm{i}$, financiados por el Ministerio de Economía y Competitividad (CSO2012-39564-C07-07) y por la Junta de Andalucía (P12-SEJ-2024). 
patrimonials). Dibuixa una proposta d'aplicació empírica que exemplifica en paisatges de diferents escales i dominants, i conclou amb una valoració crítica dels instruments utilitzats en el reconeixement patrimonial institucional i en la gestió del paisatge segons les potencialitats i les limitacions que presenta.

Paraules clau: patrimoni; paisatges patrimonials; vectors patrimonials; processos de patrimonialització; instruments de gestió

Résumé. Le nouveau paradigme du patrimoine et sa considération des paysages: concepts, méthodes et prospective

Cet article aborde le débat paysage, patrimoine et territoire à partir d'une conception du patrimoine comme assignation de valeur sociale et institutionnelle, en prenant en compte la complexité territoriale et typologique des paysages patrimoniaux. Il propose une approche conceptuelle et méthodologique de ces paysages, axée sur les acteurs économiques et leur dynamique d'appréciation (processus de patrimonialisation) et sur les éléments et arguments autour desquels se cristallise l'identification sociale et institutionnelle des paysages (vecteurs patrimoniaux). L'article ébauche une proposition d'application empirique illustrée à travers des paysages de différentes échelles et dominantes, et conclut par une évaluation critique des instruments utilisés dans la reconnaissance institutionnelle du patrimoine et de la gestion des paysages, selon leurs potentialités et leurs limites.

Mots-clés: patrimoine; paysages patrimoniaux; vecteurs patrimoniaux; patrimonialisation; instruments de gestion

Abstract. The new paradigm of heritage and its consideration regarding landscapes: Concepts, methods and prospective evolution

This article explores the landscape-heritage-territory debate from the perspective of heritage as a social and institutional attribution of values and the territorial and typological complexity of heritage landscape. A conceptual and methodological approach to these landscapes is proposed, focusing on landscape stakeholders and their appreciative dynamics ("heritagisation" processes), as well as on the elements and arguments around which social and institutional identification coalesce with landscapes (heritage vectors). The article proposes an empirical transfer that exemplifies landscapes with different dominant features and on different scales, and concludes with a critical evaluation of the instruments used in the institutional recognition of heritage and landscape management, addressing their potentials and limitations.

Keywords: heritage; heritage landscapes; heritage vectors; heritagisation; management instruments

\section{Sumari}

\section{Consideraciones previas}

2. Patrimonio y patrimonialización desde el punto de vista de los paisajes
3. Los paisajes patrimoniales.

Acercamiento metodológico y prospectivo

4. Consideraciones finales

Referencias bibliográficas 


\section{Consideraciones previas}

Los profundos cambios socioeconómicos, culturales, tecnológicos, territoriales y epistemológicos anunciados ya desde hace varios decenios han generado numerosas incertidumbres, nuevas preguntas y retos que implican redefiniciones conceptuales en buena parte de los campos científicos. En el mundo del patrimonio, se ha traducido en una sucesión de nuevos significados que han implicado importantes redefiniciones en el objeto y en el sujeto patrimonial, así como en la propia finalidad de los reconocimientos patrimoniales: desde la especie hasta el espacio en el llamado "patrimonio natural» (Gómez Mendoza, 1999); desde la valoración del monumento hasta los bienes inmateriales y los ámbitos territoriales complejos en el denominado «patrimonio cultural» (Castillo, 2009); desde la separación entre patrimonio natural y cultural hasta su creciente aproximación, mezcla y confusión (en todas las acepciones de esta palabra); desde la contemplación y la preservación hasta la utilización del patrimonio como recurso para el desarrollo de los territorios (Mata, 2008). Una nueva metamorfosis paradigmática está en marcha centrada en el citado desplazamiento de la atención patrimonial desde el objeto (o bien patrimonial) hasta el sujeto (o agente de patrimonialización). Su traslación epistemológica ha impregnado el discurso de algunas disciplinas como la antropología (Prats, 2012). En el caso de la geografía, se trata de un discurso que se está abriendo paso y que todavía está poco maduro. Este artículo pretende, como principal objetivo, adentrarse en su sistematización sin pretender agotar el debate. Para ello, se propone realizar un desarrollo metodológico que trabaje, a su vez, tres argumentos específicos:

1. Conceptual, profundizando en el debate entre patrimonio, paisaje y territorio desde la faceta de las dinámicas de apropiación y apreciación (los procesos de patrimonialización) y atendiendo a los sujetos (agentes patrimoniales), a los objetos (vectores patrimoniales —atributos en la terminología de Unesco-) y a la propia complejidad territorial y tipológica de los paisajes patrimoniales, entendiendo estos como una tipología integradora de otras tipologías de bienes patrimoniales, distinta en su complejidad y escala.

2. Metodológico, aportando algunos referentes e indicadores para el análisis de los paisajes desde un enfoque patrimonial según la relación con: a) el espacio y la localización en él de vectores patrimoniales, teniendo en cuenta la concentración en dicho espacio de tales vectores (áreas de densidad patrimonial alta, media o baja) y según su especialización o, al contrario, diversidad en uno o varios tipos de vectores patrimoniales, y $b$ ) los tiempos de las apropiaciones colectivas del patrimonio, pudiéndose diferenciar entre áreas sin patrimonializar, de patrimonialización incipiente, madura o en proceso de despatrimonialización.

3. Prospectivo, acercándose desde una perspectiva crítica a los instrumentos utilizados en el reconocimiento patrimonial institucional y avanzando hacia algunas propuestas para la gestión integral de los paisajes que tengan en cuenta qué debe protegerse, ordenarse y gestionarse en los paisajes patrimoniales y qué instrumentos son los más apropiados para ello. 
Entre los objetivos secundarios, se plantea ofrecer ejemplos del discurso teórico en dos ámbitos contrastados (rural y urbano), así como apuntar algunas ideas básicas para la gestión de los paisajes patrimoniales.

Entre las fuentes utilizadas, además de la bibliografía aportada al final del trabajo, se ha manejado información de carácter variado en los portales electrónicos del Centro del Patrimonio Mundial de la Unesco (<whc.unesco.org $>$ ) y del Consejo Internacional de Monumentos y Sitios ICOMOS (<www.icomos. org >). Para los dos ejemplos ${ }^{1}$ presentados en este trabajo (Sierra de Huelva y Málaga), se ha recurrido a la identificación de bienes patrimoniales y agentes a través, en primer lugar, de inventarios y catálogos de patrimonio y, en segundo lugar, de un exhaustivo trabajo de reconocimiento territorial, completado con la realización de entrevistas cualificadas en cada uno de ellos, además de consultar blogs y páginas web con información de interés sobre sus paisajes.

\section{Patrimonio y patrimonialización desde el punto de vista de los paisajes}

\subsection{Un concepto cada vez menos acotado y de bordes más difusos: el patrimonio}

Patrimonio y patrimonialización implican asignación de valores a determinados bienes, ya sea por parte de un grupo humano que proyecta en ellos su identidad, ya sea por parte de las instituciones (políticas, académicas, etcétera) que les atribuyen cualidades artísticas, simbólicas, conmemorativas, técnicas, etcétera. (Zamora, 2011). El patrimonio se identifica con ciertos elementos de carácter material o inmaterial (una catedral gótica, una formación natural, un oficio tradicional, etcétera), pero, en realidad, el patrimonio no es tanto el elemento en sí como el valor que se le atribuye. Su nuevo paradigma de entendimiento, tutela y gestión debe tener muy en cuenta esa premisa que invierte la realidad del estatuto contemporáneo del patrimonio, posponiendo la materialidad a la idea de esa materialidad y entendiendo el valor patrimonial en el doble carácter identitario (Agudo Torrico, 1997) e institucional (Besse, 2009) que se otorga a algunas expresiones culturales y recreaciones naturales (Beltrán et al., 2008). En términos analíticos, el acento recae en los procesos de patrimonialización (que también pueden ser de despatrimonialización, en tanto que las dinámicas de asignación de valores no son lineales, sino reversibles, y determinados elementos pueden perder interés y desvalorizarse) y en sus resultados, particularmente aquellos relacionados con el uso, la preservación y la gestión sostenible de los bienes patrimoniales (Cruz y Español, 2009).

Los axiomas en los que se sustenta ese nuevo paradigma también han cambiado, a saber:

1. El patrimonio está en la razón intelectual, en los sentimientos y en los intereses (económicos o de otro tipo), y tiene más que ver con los significados (los símbolos) que con los significantes (las realidades materiales).

1. Ejemplos extraídos de la experiencia de investigación de los autores. Han sido escogidos porque representan distintas e interesantes situaciones de las discutidas en el texto en cuanto a dominantes del carácter, escalas, vectores, procesos de patrimonialización o posibilidades de gestión. 
2. El patrimonio es siempre inmaterial, puesto que de valor se trata; lo que sí varía, y es útil para hacer operativas las políticas sobre patrimonio, es la relevancia que se otorga a la materialidad en la que se proyecta. En el valor que se atribuye a una catedral medieval, la corporeidad física del edificio es primordial, en tanto que, en los cuentos tradicionales, la materialidad física no existe más allá del cerebro y del aparato fónico del narrador. Pero, a su vez y de forma paradójica, el patrimonio inmaterial tiende a encarnarse en determinadas materialidades (una ermita en el caso de una romería, los paisajes de la agricultura en el caso de la dieta mediterránea, etcétera). En palabras de Ana Olivera «lo material y lo inmaterial son inseparables como el cuerpo y el alma de un territorio» (2011: 668).

3. Las divisiones tradicionales del patrimonio (tangible/intangible, cultural/ natural) pierden relevancia y la propia existencia de un patrimonio natural se plantea como incongruente, en la medida en que todo el patrimonio, en tanto que construcción social, es cultural. Aunque operativamente siguen siendo útiles las expresiones de patrimonio natural y patrimonio cultural, se entiende que el reconocimiento y la protección de la naturaleza son hechos culturales. A título de ejemplo, hace apenas dos generaciones, Doñana era considerada un territorio insalubre donde se corría el riesgo de contraer el paludismo y hoy es valorada como un santuario de la naturaleza. Sus múltiples y solapados reconocimientos institucionales (parque nacional, reserva natural, parque natural, reserva de la biosfera, inclusión en la Lista de Patrimonio Mundial de Unesco, etcétera) o, lo que es lo mismo, su patrimonialización institucional, no han sido ajenos a esos cambios.

4. El patrimonio, más que con el pasado, tiene que ver con el presente. El concepto de patrimonio histórico rompió costuras cuando dejó de tener valores ajustados a tiempos pretéritos y definidos y, sobre todo, a raíz de la evolución desde el concepto de patrimonio histórico hasta el de patrimonio cultural en los últimos decenios del siglo xx. Los valores están en transformación continua, pero el patrimonio es siempre presente, aunque, como una paradoja más, la antigüedad siga siendo un criterio básico en la identificación de los bienes culturales, dado que es un valor en sí misma. Las identidades cambian, se mueven y, aunque parezca que a veces vuelven al mismo punto, nunca es así. Los valores institucionales tampoco son estáticos y la propia evolución en la consideración legal del patrimonio así lo atestigua. El patrimonio se construye y se recrea continuamente, por lo tanto debe aceptarse que el patrimonio es rabioso presente.

Si se admite que el patrimonio es un valor sometido a cambios, identitarios o de consideración institucional, es más fácil entenderlo como un proceso que como una realidad estática. De ahí la importancia de entender y tener presentes los procesos de patrimonialización.

El debate entre un patrimonio de origen identitario, que se construye de abajo arriba (Clark y Drury, 2002), y otro institucional, que deviene de una dirección arriba abajo (Prats, 1997; Besse, 2009), se combina con aquel otro 
centrado en los propósitos de las declaraciones. Desde una intención académica, estética y conservacionista, se ha pasado a priorizar la utilización del patrimonio con fines económicos y como instrumento de desarrollo territorial a través de su activación mediante actividades turísticas. Se ha llegado incluso a señalar que el turismo desempeña un papel clave en los procesos de patrimonialización (Prats, 1998) y que el concepto de patrimonio cultural es un subproducto del de turismo cultural (Almirón et al., 2006).

Otro aspecto de interés tiene que ver con las modificaciones operadas en el reconocimiento legal y en la tutela del patrimonio. Se ha avanzado desde su consideración institucional en compartimentos estancos (patrimonio cultural frente a patrimonio natural) hacia una nueva visión en la que el patrimonio lo impregna todo y se inserta en otras políticas. Tal andadura ha sido particularmente vigorosa entre las instituciones del llamado "patrimonio natural», que son mucho más tardías que las del patrimonio cultural, que se conforman en el siglo XIX y con antecedentes desde el anterior. Las del patrimonio natural, aunque aparecen en la primera mitad del siglo xx, empiezan a tener mayor calado social a partir de los años setenta con la generalización de movimientos ecologistas. Sin embargo, y no sin profundas resistencias (como los pobres resultados del Protocolo de Kyoto), han conseguido situarse en la médula del sistema y hoy sus axiomas impregnan trasversalmente las grandes políticas nacionales e internacionales. Un ejemplo de esto lo ofrece la política agraria comunitaria (PAC). En ella, el discurso ambiental ha alcanzado, primero tímidamente, a las políticas estructurales y de desarrollo rural (medidas agroambientales, programas de reforestación del segundo pilar) hasta llegar a su núcleo duro (a través de la ecocondicionalidad o del denominado greening o compromiso verde del primer pilar). Aunque todavía queda mucho camino por recorrer, ello abre importantes expectativas para la gestión de los paisajes patrimoniales de raigambre agropecuaria, al menos desde el punto de vista de su sostenibilidad ambiental.

Los pensadores, gestores y activistas del patrimonio cultural, en cambio, han sido menos audaces. No ha habido una cumbre de Río para la cultura, cuando, sin duda, todas las culturas del mundo salvo la llamada «occidental» están en un peligro tan grande o mayor que la salud ambiental del planeta. Mientras el discurso ecologista se ha legitimado en la sociedad, el cultural sigue siendo percibido a menudo, y no sin razón, como elitista y conservador. Un ejemplo de ello lo ofrece la herencia de la aportación intelectual italiana sobre centros históricos de los años setenta del siglo pasado, que ha influido notablemente en los aspectos formales de muchos de ellos, pero que renunció, casi desde sus inicios y pese a la ideología progresista de sus autores, a constituir una herramienta de equilibrio social dentro de la ciudad. El término gentrificación, que no es otra cosa que el aburguesamiento de sectores urbanos, aparece casi al mismo tiempo que las teorías y las prácticas civiles que trataban de impedir que las clases sociales modestas, populares y cargadas de sentimiento de pertenencia al lugar fueran desplazadas de sus lugares de residencia tradicional, especialmente de los centros históricos (Díaz Parra, 2015). 
Otro debate, también incierto y resbaladizo, aunque cada vez más extendido, tiene que ver con las conexiones entre el patrimonio y el territorio donde se ubica. Todo el siglo xx significó el paso de pensar puntualmente - o simplemente aespacialmente - los bienes patrimoniales, a considerar, primero, entornos, luego centros históricos y cada vez figuras territoriales más amplias y complejas que pretenden ser holísticas y difíciles de determinar con el saber hacer del campo patrimonial tradicional. Entre ellas se encuentran, sobre todo, los itinerarios y los paisajes culturales (Maderuelo, 2012).

\subsection{La construcción social del patrimonio desde la perspectiva de los paisajes}

El hombre, por más que se mueva sobre el mundo, permanece atado a su primer paisaje.

(Juan Antonio Cabezas, 1956: 349)

Todos los paisajes de las zonas habitadas del planeta son patrimoniales, en tanto que forman parte de la identidad de sus habitantes. Este axioma se reconoce siempre en las escalas locales, próximas al individuo y a su campo de experiencias. Sin embargo, hay paisajes cuyo valor patrimonial trasciende esa escala local y son valorados por individuos o instituciones de rango supralocal. Estos son los que interesan en el presente artículo.

El debate sobre el nuevo paradigma patrimonial aplicado a los paisajes adquiere un significado particular. El concepto de paisaje, que es igualmente resbaladizo y cambiante (Martínez de Pisón, 2013), combinado con el de patrimonio adquiere una especial complejidad (Gómez Mendoza, 2013). En este contexto, se proponen los siguientes axiomas:

a) Si bien todos los paisajes son potencialmente patrimonializables, hay que tener en cuenta que la patrimonialización implica selección, y los paisajes patrimoniales deben circunscribirse a aquellos que sean merecedores de reconocimiento y protección (Mata et al., 2012).

b) Un paisaje se convierte en patrimonial como consecuencia de su apropiación y de los valores que le son asignados. Estos procesos de patrimonialización poseen una doble dirección: de abajo arriba, cuando el agente patrimonializador es la base social (Obbelaar y Pedroli, 2011); y de arriba abajo, cuando el agente es el conjunto de instituciones académicas, legales y administrativas (Arnese, 2011).

c) Los reconocimientos patrimoniales son selectivos, pues se concretan en los vectores de patrimonialización. Se trata de aquellos elementos que componen los paisajes que poseen un valor identitario atribuido por la población local (en la patrimonalización abajo arriba) o reciben un reconocimiento histórico, artístico, simbólico o similar desde las instituciones (en la patrimonialización arriba abajo). En algunos casos, pueden actuar como vectores los monumentos naturales y culturales (colinas sagradas, cuevas, fuentes, estructuras defensivas, etcétera); en otros, los vectores son líneas o ejes (caminos de peregrinación, canales históricos, rutas comerciales 
tradicionales); en otros, la condensación patrimonial se opera sobre usos económicos (antiguos núcleos industriales, regadíos tradicionales, sistemas agrosilvopastoriles) o bienes inmateriales (tradición oral, gastronomía local, artesanía, etcétera) (Fernández y Silva, 2015).

d) Las escalas de los paisajes, patrimoniales o no, son las escalas medias: comarcales y locales. Determinadas piezas o elementos (un monasterio, un molino, una fuente) pueden actuar como vectores patrimoniales o constituir hitos paisajísticos relevantes, pero en sí mismos no son paisajes. Otro tanto cabe señalar respecto a las escalas regionales (el paisaje mediterráneo, el paisaje manchego) y a los paisajes con una determinada dominante (de dehesas, de olivares, de marismas), que tampoco son paisajes patrimoniales propiamente dichos, sino abstracciones o tipos de paisajes (según la nomenclatura de la Countryside Agency and Scottish Natural Heritage, 2002). Las adhesiones patrimoniales se organizan en torno a paisajes concretos, puesto que nadie se identifica con los conjuntos históricos en su generalidad, sino con los de su ciudad. Sea como fuere, las escalas medias son extremadamente variables, puesto que abarcan desde pequeños núcleos rurales y sus entornos hasta comarcas enteras donde los paisajes urbanos y rurales se imbrican unos en otros a modo de muñecas rusas. Así pues:

- En los paisajes patrimoniales, las escalas no son solo territoriales, sino que también existen las escalas perceptivas, dependiendo del alcance de las identidades patrimoniales, de los observadores potenciales (paisajes patrimoniales de identificaciones socioidentitarias locales y globales) y según los rangos de los reconocimientos patrimoniales (paisajes patrimoniales de rango local, regional, nacional e internacional).

- Internamente, los paisajes (patrimoniales o no) son unidades territoriales complejas y completas. Están integrados por una superposición de capas espaciales (estructuras físico-naturales, usos del suelo, unidades de poblamiento, vías de comunicación, etcétera) y temporales (gestadas en distintos momentos históricos). A efectos analíticos, resulta muy operativa la descomposición de esas capas (se habla de paisajes mineros, de paisajes de viñedo, de paisajes urbanos medievales, de paisajes de arquitectura renacentista, etcétera), pero los paisajes son totalizadores territoriales e históricos, por lo que también hay que hacer el ejercicio contrario de recomposición de tales capas en el conjunto del paisaje, donde a menudo menguan en su significado.

- En tanto que unidades territoriales complejas y completas, los paisajes patrimoniales contienen elementos de especial valor patrimonial (los vectores patrimoniales), junto a otros componentes del paisaje/territorio que no tienen por qué poseer valores reconocidos y ni tan siquiera unas cualidades estéticas especiales. No todo en los paisajes puede o debe ser conservado. El paisaje es, en esencia, dinamismo y se resiste a la musealización, por lo que las actuaciones relacionadas con el orden en la estructura territorial y con la gestión de los cambios resultan básicas para la preservación de sus valores. 
En función del proceso de patrimonialización que los legitima, los paisajes patrimoniales son, pues, o bien aquellos que proporcionan identidad a sus habitantes, y cuya valoración es lógicamente local, o bien aquellos que poseen un reconocimiento institucional que, por lo general, trasciende lo local y les asigna valores de rango regional, nacional o internacional. Estos paisajes, en todo caso, son un bien patrimonial que se genera a partir de otros bienes patrimoniales, aunque el resultado, al integrar elementos que tienen valor patrimonial y otros que no, es una realidad patrimonial distinta, ya que cada uno de los elementos se redimensiona espacial y simbólicamente a partir de su relación con los demás y con el territorio en su conjunto. Estos paisajes están integrados por una serie de elementos, tangibles e intangibles, entre los que unos tienen valor patrimonial en sí mismos (vectores) y otros no. Este razonamiento lleva a otras disquisiciones: si patrimonialización implica selección, ¿qué paisajes merecen la consideración de paisajes patrimoniales por la presencia de estos vectores? ¿Todos los bienes patrimoniales son vectores de patrimonialización de un paisaje? Y, si no es así, cuándo y por qué un elemento patrimonial en el territorio se convierte en vector que patrimonializa al paisaje en el que se inserta?

La Unesco utiliza una serie de condiciones acreditativas del valor universal excepcional que deben ser satisfechas por los bienes que se incluyen anualmente en la Lista del Patrimonio Mundial. Estas condiciones, aunque poco precisas, pueden resultar orientadoras y, de ellas, son particularmente importantes las que atañen a la autenticidad y a la integridad. Se asume como autenticidad la capacidad de mantener los significados originales e identitarios de un bien, en tanto que la integridad informa sobre la parte del bien que condensa los valores patrimoniales y cómo se inserta esa parte en el conjunto. En otras palabras, la autenticidad tiende a la abstracción, en tanto que la integridad tiende a la identificación material de los valores. Podría considerarse que el reconocimiento de abajo arriba, orgánico e identitario, está más cercano a los parámetros de autenticidad; en cambio, los valores institucionales, por lo general más interesados en los aspectos materiales del bien, especialmente en una cultura como la occidental, se aproximan más a la determinación de la integridad. En los paisajes patrimoniales, podría decirse que la integridad tiene que ver con el grado de conservación de sus vectores patrimoniales y con la capacidad de estos de interactuar con otros elementos espaciales conformando el orden de la estructura territorial, y que la autenticidad es lo contrario a la tematización, que tiene mucho que ver con la veracidad de los paisajes y con la preservación de sus funciones y de sus significados.

La ampliación territorial de los significados del patrimonio ha implicado importantes cambios en la legitimación y en la selección de los bienes patrimoniales. Cuando el objeto patrimonial se circunscribía a elementos concretos (monumentos, museos, zonas arqueológicas), la selección no era importante por obvia y acotada, y la integridad y la autenticidad estaban resueltas porque los bienes solo se entendían en sí mismos, eran aterritoriales y se los consideraba como si flotasen en la nada. Con el siglo xx llega el momento de pensar estos bienes en el territorio, primeramente en ámbitos acotados (entornos, conjuntos 
históricos, zonas de amortiguamiento, etcétera); posteriormente, en los últimos decenios del siglo, se apunta directamente al territorio, no ya como escenario patrimonial, sino como protagonista. Es en este contexto en el que hay que entender la emergencia y la relevancia de los paisajes patrimoniales. El paulatino protagonismo del territorio como objeto patrimonial también tiene su propia evolución. Primero se identifican distintas capas patrimoniales (zonas monumentales, abrigos prehistóricos, patrimonio etnográfico, etcétera), pero de manera inconexa cada una de ellas. En tales circunstancias, continúa siendo relativamente sencillo identificar la autenticidad y la integridad de un bien. El salto cualitativo se produce cuando el territorio se convierte en patrimonio y la autenticidad y la integridad deben considerarse en un espacio de geometrías variables, donde todas las capas patrimoniales interactúan entre sí y se integran en ese conjunto territorial.

Las razones que justifican el carácter patrimonial de los paisajes apenas han sido esbozadas más allá de los citados conceptos utilizados por la Unesco (Silva y Fernández, 2015). Un repaso de la literatura existente sobre los conceptos de patrimonio y de paisaje subraya otros principios como la antigüedad (Flys y Sanz, 2010), la potencia identitaria (Ortega Cantero, 2009), el carácter telúrico de las montañas (Martínez de Pisón, 2012) o las connotaciones o cualificaciones simbólicas de las miradas creativas desde la literatura, la pintura, el cine, la fotografía, etcétera (López Ontiveros, 2006). Estas últimas son particularmente relevantes por su capacidad para reavivar el aprecio social por los paisajes, para reforzar su excepcionalidad y para mejorar el rango perceptivo de algunos de ellos (por ejemplo: el paisaje de Arles tamizado por la mirada de Van Gogh traspasa la escala perceptiva local y adquiere una dimensión internacional). Se trata, también en este caso, de aspectos muy generales y poco discriminatorios (ya que de selección se trata) y que requieren de una mayor profundización.

\section{Los paisajes patrimoniales. Acercamiento metodológico y prospectivo}

\subsection{Hacia una propuesta analítica}

El debate epistemológico sobre el nuevo paradigma del patrimonio desde la perspectiva de los paisajes no puede limitarse al ámbito conceptual, puesto que precisa de planteamientos metodológicos y de fuentes novedosas que faciliten la implementación territorial de algunos de sus axiomas como paso previo e ineludible para el avance hacia planteamientos prospectivos.

Es este un aspecto que no está en absoluto cerrado y sobre el que se sigue trabajando en el marco del programa de investigación donde se inserta el presente artículo. El estado actual del estudio permite el bosquejo de un procedimiento para la identificación, la sistematización y la descripción de los vectores de los paisajes patrimoniales a partir del tratamiento diferenciado de sus bienes materiales (distribuidos, a su vez, según se trate de elementos puntuales, lineales o áreas) e inmateriales. Como fuentes de información, en el caso de la patrimonialización de arriba abajo (o institucional), cabe recurrir a los inventarios de espacios naturales protegidos y a los catálogos generales de 
Tabla 1. Vectores patrimoniales y sus tipos en los paisajes serranos onubenses

\section{Vectores materiales}

\section{Elementos de carácter puntual}

- Monumentos naturales: Encina de la dehesa de San Francisco (Cala).

- Cerros, algunos de ellos con vestigios de antiguos asentamientos neolíticos y calcolíticos: El Castañuelo (Aracena); el Pico de los Ballesteros, Las Peñas y Cerro Borrero (Aroche).

- Cuevas y oquedades, muchas de ellas utilizadas como hábitat prehistórico desde el neolítico hasta la edad del bronce: Cuevas de la Umbría (Aracena), de la Mora (Jabugo), de Navahermosa (Fuenteheridos). Las más conocidas y conspicuas son el abrigo de la Peña de Arias Montano y las Grutas de las Maravillas de Aracena.

— Dólmenes megalíticos y tholos: Los Praditos, La Belleza, Monteperro y Montero (Rivera del Chanza-Aroche); Monte Costa (Zufre) y Los Llanos (Puerto Moral); Puerto de los Señoritos (Rivera del Múrtiga-Encinasola).

- Monumentos funerarios: El Becerrero y Santa Eulalia (Almonaster), Castañuelo-La Dehesilla (Aracena), La Puente y La Gomera (Corteconcepción), Monte Costa (Zufre).

— Ciudades romanas: Turóbriga (Aroche).

— Edificaciones romanas dispersas: El Prado o La Boticaria II (Zufre), Corteganilla II (Cortegana), El Vínculo (Aroche), Fuente del Oro (Almonaster), Santa Ana (Puerto Moral).

— Restos mineros romanos: Mina Sotiel Coronada (Aracena), Mina María Luisa (La Nava), minas de La Jineta y La Sultana (Cala).

- Castillos: de época islámica (Almonaster la Real, Aracena [figura 1], Aroche y Zufre); de finales del siglo XIII (Santa Olalla del Cala, Encinsola, Cortegana, Cumbres Mayores), y fortificaciones del siglo XVI (fuertes de San Juan y San Felipe en Encinasola).

— Ermitas: San Mamés (Aroche); Santa Eulalia (Almonaster la Real); Virgen de la Tórtola (Hinojales); San Bartolomé (Alájar); Santa Brígida (Galaroza); Los Remedios (Arroyomolinos de León); Nuestra Señora de la Coronada (Cortelazor); Virgen de la Amparo (Cumbres Mayores); Virgen de Rocamador y Virgen de las Flores (Encinasola); San Sebastián (Higuera de la Sierra); Virgen de Gracia (La Nava), y San Salvador (Puerto Moral).

- Cortijos serranos y otras edificaciones agrarias dispersas en el medio rural: casas monte, bujardas o chozos, casas de labor con solanas en las áreas de huerta.

— Infraestructuras relacionadas con el agua: aljibes, fuentes, lavaderos, molinos hidráulicos.

— Plazas de toros: Castaño del Robledo, Almonaster la Real, Aroche, Cumbres Mayores, Campofrío.

\section{Elementos lineales}

- Cursos de agua jalonados por bosques galería.

- Ejes de comunicación: restos de la vía romana Riotinto-Aroche-Beja; antigua línea ferroviaria Minas de Cala-San Juan de Aznalfarache; caminos rurales, y vías pecuarias.

- Restos de acueductos romanos: Fuente Seca.

- Sistemas de acequia (lievas).

— Muros de piedra seca (en ruedos y dehesa).

\section{3. Áreas}

- Entramados urbanos (medievales y nuevas poblaciones de tejido urbano planificado).

- Huertas y regadíos tradicionales.

- Bosques de castaños.

- Dehesas.

\section{Vectores inmateriales}

- Romerías: algunas de ellas de carácter supralocal: Nuestra Señora de los Ángeles (Alájar), San Mamés (Aroche), Santa Eulalia (Almonaster) y San Antonio (Cortegana).

— Fiestas populares: Cruces de Almonaster, Cabalgata de Reyes Magos de Higuera de la Sierra, fiesta de los Jarritos (Galaroza), fiesta de los Rehiletes (Aracena).

- Danzas y rituales: danza de Hinojales, danzantes del Lunes de Albilillo (Cumbres Mayores), antiguas danzas del Pañuelo (Encinasola).

- Cantes: fandango morocho de Encinasola, jota serrana, canciones tradicionales.

- Tradición oral: cuentos y leyendas serranas.

- Artesanías: carpinterías de Galaroza, alfarerías de Aracena y Cortegana, fábrica de romanas de Cortegana, guarnicionería de Aroche.

- Oficios tradicionales.

Fuente: Silva y Jover, en prensa. 


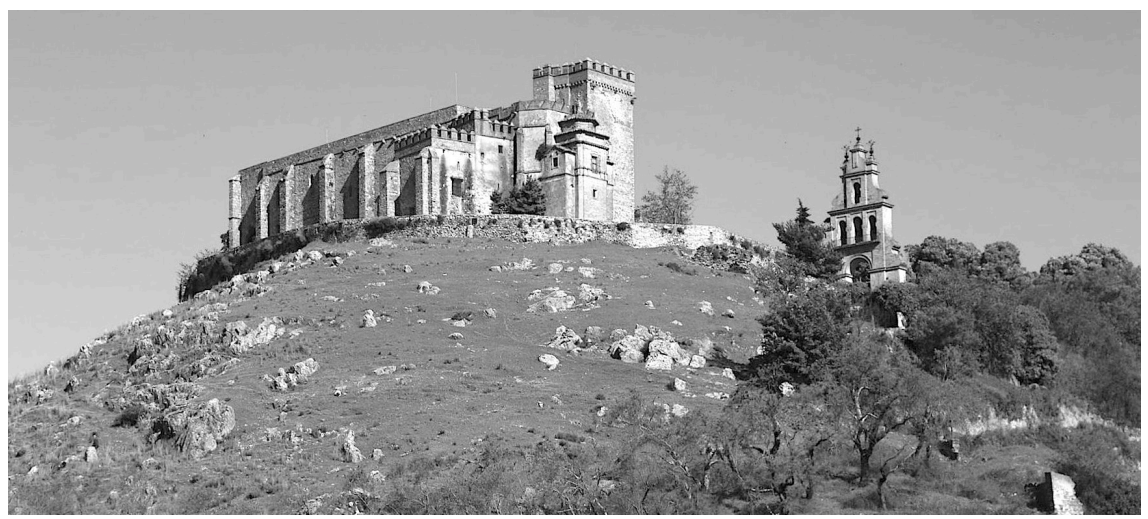

Figura 1. Castillo de Aracena.

Fuente: elaboración propia.

patrimonio, sean estos internacionales, nacionales, regionales o locales. Para la patrimonialización de abajo arriba, resulta útil la identificación de los agentes que la generan, con su tejido asociativo y su visibilidad en las redes sociales. En la tabla 1 puede apreciarse como ejemplo la aplicación de esa sistematización metodológica a la sierra de Huelva (Silva y Jover, en prensa).

También se ha avanzado en el planteamiento de referencias para reconocer dónde se sitúan los valores patrimoniales de los paisajes (véase la tabla 2).

Desde la perspectiva de la apropiación patrimonial o, lo que es lo mismo, atendiendo a los procesos de patrimonialización, se han planteado distintas categorías (alta, media y baja) que permitan expresar la intensidad patrimonial dentro de los paisajes, así como las dinámicas de apropiación o valoración socioinstitucional de determinadas partes de estos (áreas sin patrimonializar, de patrimonialización incipiente, madura o en proceso de des-

Tabla 2. Los paisajes patrimoniales: tiempo y espacio

\begin{tabular}{ll}
\hline Tiempo: los procesos de patrimonialización & Espacio: los vectores patrimoniales \\
\hline $\begin{array}{l}\text { Determinación de la intensidad patrimonial en } \\
\text { función del número y del carácter de los agen- } \\
\text { tes implicados: }\end{array}$ & $\begin{array}{l}\text { Determinación de la densidad patrimonial en } \\
\text { función de la presencia y de la distribución de } \\
\text { vectores: }\end{array}$ \\
$\begin{array}{ll}\text { - Áreas de intensidad patrimonial alta, media } \\
\text { y baja. }\end{array}$ & $\begin{array}{c}- \text { Áreas de densidad patrimonial alta, media } \\
\text { y baja. }\end{array}$ \\
\hline $\begin{array}{l}\text { Determinación de las dinámicas de apropiación } \\
\text { en función del estadio del proceso: }\end{array}$ & $\begin{array}{l}\text { Determinación de la especialización y de la } \\
\text { diversificación patrimonial en función de los }\end{array}$ \\
$\begin{array}{l}\text { - Áreas sin patrimonializar / de patrimoniali- } \\
\text { zación incipiente / madura / en proceso de } \\
\text { despatrimonialización. }\end{array}$ & $\begin{array}{l}\text { tipos de vectores: } \\
\text { Áreas patrimoniales especializadas (monu- }\end{array}$ \\
& - Áreas de patrimonio diversificado.
\end{tabular}

Fuente: elaboración propia. 
Tabla 3. El paisaje patrimonial de Málaga: tiempo y espacio

\begin{tabular}{|c|c|}
\hline Tiempo: los procesos de patrimonialización & Espacio: los vectores patrimoniales \\
\hline Intensidad patrimonial: & \multirow{6}{*}{$\begin{array}{l}\text { Densidad patrimonial: } \\
\text { - Ciudad histórica preindustrial: alta. } \\
\text { - Litoral oriental: media. } \\
\text { - Litoral occidental: baja. } \\
\text { - Puerto: media. } \\
\text { - Cauce del río Guadalmedina y Montes de } \\
\quad \text { Málaga: media-alta. }\end{array}$} \\
\hline $\begin{array}{l}\text { - Ciudad histórica preindustrial: alta (centro } \\
\text { histórico y monte de Gibralfaro [figura 2]). }\end{array}$ & \\
\hline $\begin{array}{l}\text { - Litoral oriental: media (astilleros Nereo [figura } \\
\text { 3], balneario de los Baños del Carmen, cultu- } \\
\text { ra pesquera, gastronomía [espetos]). }\end{array}$ & \\
\hline $\begin{array}{l}\text { - Litoral occidental: medio (con nuevas asig- } \\
\text { naciones patrimoniales a antiguas fábricas } \\
\text { [figura 4] y equipamientos como La Térmica). }\end{array}$ & \\
\hline \multirow{2}{*}{$\begin{array}{l}\text { - Puerto: alta (muelles } 1 \text { y } 2 \text { [figura 5]). } \\
\text { - Cauce del río Guadalmedina y Montes de } \\
\text { Málaga (figura 6): baja }\end{array}$} & \\
\hline & \\
\hline \multirow{7}{*}{$\begin{array}{l}\text { Dinámicas de apropiación: } \\
\text { - Ciudad histórica preindustrial: área de patri- } \\
\text { monialización madura. } \\
\text { - Litorial oriental: área en proceso de despa- } \\
\text { trimonialización. } \\
\text { - Litoral occidental: áreas de patrimonializa- } \\
\text { ción incipiente. } \\
\text { - Puerto: área de reciente patrimonialización. } \\
\text { - Cauce del río Guadalmedina y Montes de } \\
\text { Málaga: áreas sin patrimonializar o con } \\
\text { problemas para incorporar valores patrimo- } \\
\text { niales. }\end{array}$} & Especialización y diversificación patrimonial: \\
\hline & $\begin{array}{l}\text { - Ciudad histórica preindustrial: alta (vectores } \\
\text { patrimoniales diversos, pero con predomi- } \\
\text { nancia de monumentos y museos). }\end{array}$ \\
\hline & \\
\hline & $\begin{array}{l}\text { patrimonio etnológico: carpintería de ribera, } \\
\text { saberes tradicionales de la pesca, gastrono- } \\
\text { mía, etcétera). }\end{array}$ \\
\hline & $\begin{array}{l}\text { - Litoral occidental: alta (especialización en } \\
\text { patrimonio industrial y nuevos museos). }\end{array}$ \\
\hline & $\begin{array}{l}\text { - Puerto: alta (infraestructuras portuarias y } \\
\text { museo). }\end{array}$ \\
\hline & $\begin{array}{l}\text { - Cauce del río Guadalmedina y Montes de } \\
\text { Málaga: baja, diversificada e inconexa (jar- } \\
\text { dines históricos, yacimientos arqueológicos, } \\
\text { cultura del agua, etcétera, y con un impor- } \\
\text { tante peso del patrimonio natural [parque } \\
\text { natural]). }\end{array}$ \\
\hline
\end{tabular}

Fuente: elaboración propia.

patrimonialización). Desde una perspectiva territorial se han planteado categorías para mostrar la densidad patrimonial (alta, media y baja) o el grado de especialización o diversificación patrimonial de las diferentes subáreas paisajístico-patrimoniales. Como fuentes de información, se ha recurrido, para la patrimonialización de arriba abajo, a la identificación de las instituciones implicadas en los reconocimientos patrimoniales (administraciones ambiental y cultural, ayuntamientos, etcétera) y a la afección territorial de sus propuestas y proyectos (planes de desarrollo sostenible, planes generales de ordenación urbanística, planes estratégicos, etcétera). En la patrimonialización de abajo arriba, se han tenido en cuenta los tejidos asociativos (asociaciones culturales, grupos ecologistas, plataformas ciudadanas, etcétera) y las afecciones territoriales de sus propuestas.

A título ilustrativo, la aplicación del esquema anterior a los paisajes urbanos malagueños (tabla 3 y figuras 2 a 6) ha permitido realizar la identificación de 


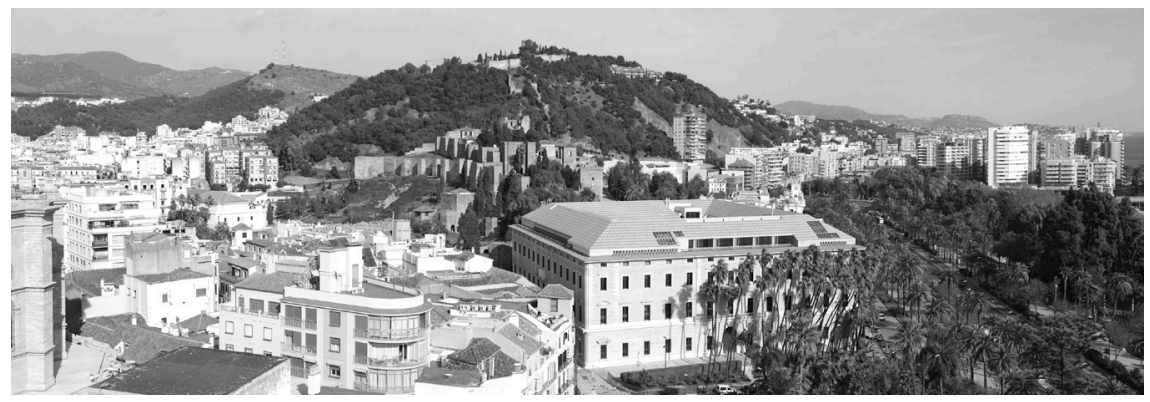

Figura 2. Vista parcial del centro histórico y del monte de Gibralfaro.

Fuente: elaboración propia.

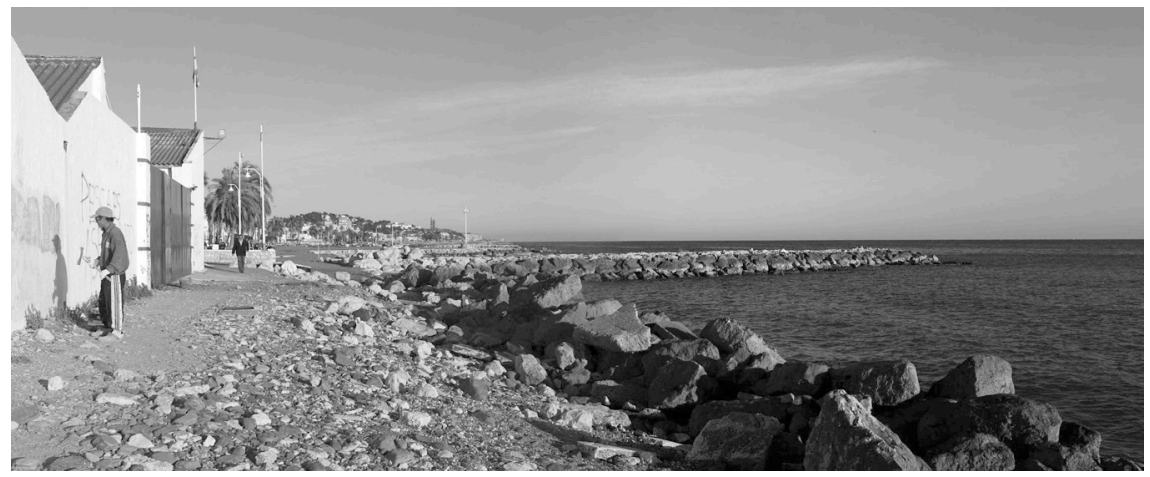

Figura 3. Fachada al mar de los astilleros Nereo.

Fuente: elaboración propia.

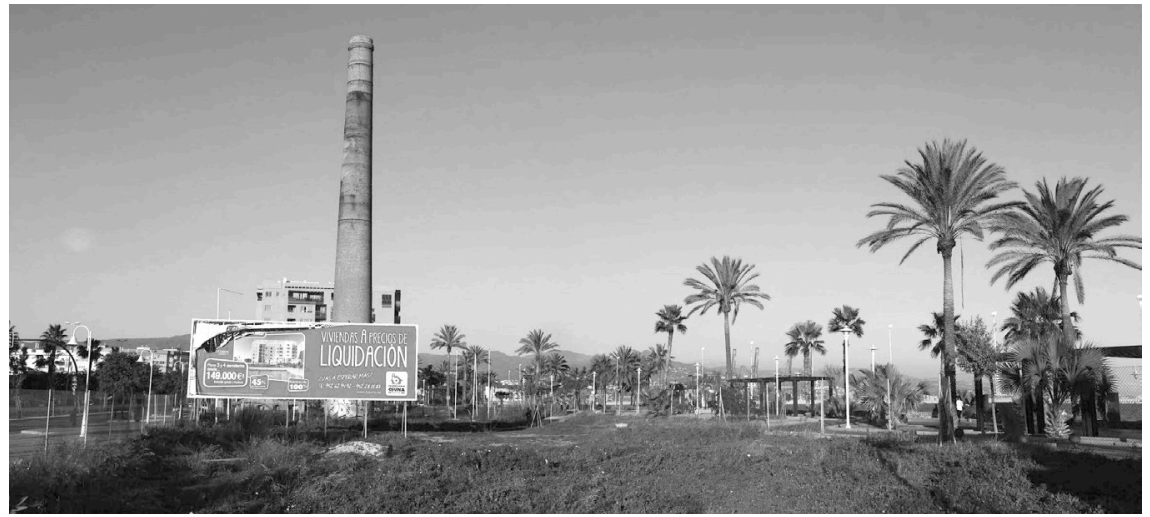

Figura 4. Chimenea de la antigua fábrica de abono La Trinidad.

Fuente: elaboración propia. 


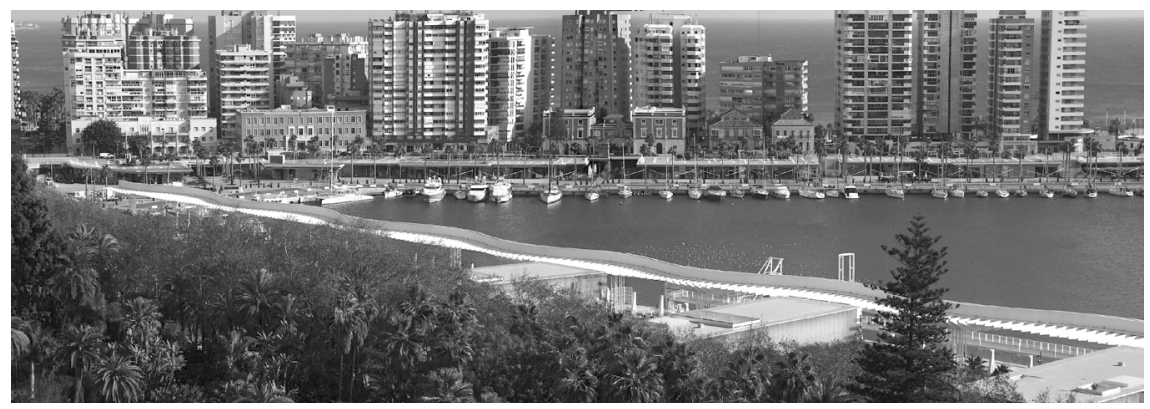

Figura 5. Vista frontal del Muelle 1 del puerto.

Fuente: elaboración propia.

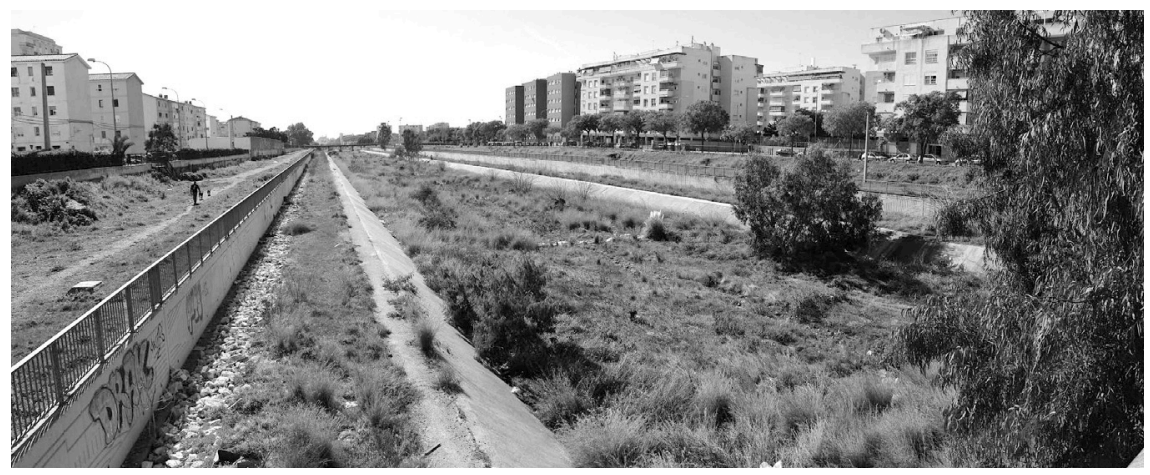

Figura 6. Cauce del río Guadalmedina.

Fuente: elaboración propia.

diferentes subáreas en lo que a densidad y tipologías de sus vectores patrimoniales se refiere:

a) La ciudad histórica preindustrial, con una elevada densidad patrimonial de tipo monumental y museístico.

b) El litoral oriental, con una densidad patrimonial media y con una importante presencia del patrimonio etnográfico, aunque en grave riesgo de pérdida de valores.

c) El litoral occidental, con una baja densidad patrimonial y especializado en arqueología industrial.

d) El puerto, en proceso de reafirmación patrimonial y adquiriendo nuevos referentes y grandes transformaciones de los muelles 1 y 2 .

e) El cauce del río Guadalmedina y los Montes de Málaga, espacios donde los vectores de tipo natural son muy potentes, pero que, a pesar de algunas iniciativas no desdeñables, no han sido apropiados patrimonialmente por la ciudad. 
A su vez, los indicadores de intensidad y de dinámicas de apropiación aplicados al mismo caso permiten distinguir entre:

a) Una zona de intensas y maduras expresiones patrimoniales y en proceso de reinvención a partir de nuevos parámetros (los museos), que, a grandes rasgos, viene a coincidir con la ciudad histórica preindustrial y el litoral occidental.

b) Un área de incipiente patrimonialización, donde la reinvención patrimonial y la oferta museística es particularmente significativa, con dos ubicaciones: la zona portuaria y, a su vez, el litoral occidental.

c) Un área en proceso de despatrimonialización coincidente con el litoral oriental especializado en patrimonio etnográfico.

\subsection{La patrimonialización de los paisajes y sus instrumentos: Claves para un análisis prospectivo}

Los cambios operados en el paradigma del patrimonio se acompañan de modificaciones no menos importantes en los propósitos de los reconocimientos, dándose ahora prelación al uso de los bienes patrimoniales como recurso para el desarrollo de los territorios (Feria, 2013; Pérez y Parra, 2004). Esta es una intencionalidad básica y omnipresente en políticas, programas y proyectos relacionados con el turismo (Troitiño y Troitiño, 2010). Dicha pauta, especialmente en un contexto como el español, se aplica de manera indiscriminada a distintos tipos de bienes (monumentales, arqueológicos y minero-industriales [Hortelano, 2011]); conjuntos históricos y áreas urbanas en declive (Troitiño, 1998; Zárate, 2011); espacios naturales protegidos (Muñoz, 2008), y ámbitos rurales (Bel y Arranz, 2011). Esta activación del patrimonio, compartida por agentes turísticos y políticos locales, tiende a homogeneizar aquello que es diferente.

Las consecuencias no deseadas de la asimilación entre turismo y desarrollo territorial han sido recurrentemente denunciadas (Zárate, 2011; Hernández y Hernández, 2015; Vázquez y Martín, 2011). Generalmente, las recriminaciones se sustentan en el deterioro ocasionado por un uso turístico desmedido. Raramente se menciona como un problema, $\mathrm{u}$ origen de problemas, la consideración de los bienes patrimoniales de manera autista y desvinculados de los territorios y la consiguiente merma de los valores que aporta al conjunto, una cualidad fundamental en los paisajes, o las pérdidas de integridad y coherencia que de ello se derivan, también básicas de cara a la legitimación del patrimonio. Esa desvinculación espacial de los bienes patrimoniales se explica en el extendido razonamiento de que su sola activación redundará en beneficio de los territorios. Hay una producción científica sobre la relación entre patrimonio y desarrollo que supera los dos decenios, pero es frustrante buscar valoraciones y trabajos prácticos que demuestren de qué forma (cuantitativa y cualitativa) el patrimonio contribuye a fomentar el desarrollo de los territorios (Fernández Salinas, 2003; Prats, 2012).

En los paisajes patrimoniales, que en esencia son espacios dinámicos, vividos y funcionales, ni la preservación es asimilable a la conservación ni el uso de 
Tabla 4. Hacia una gestión integral de los paisajes patrimoniales. Políticas, instrumentos y actores

\begin{tabular}{|c|c|c|c|}
\hline $\begin{array}{l}\text { Dominantes } \\
\text { paisajísticas }\end{array}$ & Políticas & Instrumentos & Actores \\
\hline Natural & $\begin{array}{l}\text { - Conservación } \\
\text { de la naturaleza. } \\
\text { - Políticas territoriales. }\end{array}$ & $\begin{array}{l}\text { - Planes de ordenación } \\
\text { de los recursos natu- } \\
\text { rales (PORN). } \\
\text { - Planes rectores de uso } \\
\text { y gestión (PRUG). } \\
\text { - Planes de ordenación } \\
\text { del territorio de ámbito } \\
\text { subregional. }\end{array}$ & $\begin{array}{l}\text { - Administración } \\
\text { ambiental. } \\
\text { - Administración } \\
\text { territorial. } \\
\text { - Juntas rectoras de } \\
\text { espacios naturales } \\
\text { protegidos. } \\
\text { - Asociaciones } \\
\text { ecologistas. }\end{array}$ \\
\hline Rural & $\begin{array}{l}\text { - Políticas agrarias. } \\
\text { - Ordenación } \\
\text { del territorio. } \\
\text { - Políticas culturales. } \\
\text { - Desarrollo rural. }\end{array}$ & $\begin{array}{l}\text { - Política agraria común } \\
\text { (PAC). } \\
\text { - Planes de ordenación } \\
\text { del territorio de ámbito } \\
\text { subregional. } \\
\text { - Declaraciones de bie- } \\
\text { nes de interés cultural. } \\
\text { - Planes especiales. } \\
\text { - Planes y programas } \\
\text { de desarrollo rural. } \\
\text { - Denominaciones de } \\
\text { origen, indicaciones } \\
\text { geográficas protegidas } \\
\text { y certificaciones de } \\
\text { agricultura ecológica. }\end{array}$ & $\begin{array}{l}\text { - Administración } \\
\text { agraria. } \\
\text { - Administración } \\
\text { territorial. } \\
\text { - Administración } \\
\text { cultural. } \\
\text { - Grupos de desarrollo } \\
\text { local. } \\
\text { - Organizaciones y } \\
\text { sindicatos agrarios. } \\
\text { - Consejos reguladores } \\
\text { de denominaciones } \\
\text { de origen. }\end{array}$ \\
\hline Urbana & $\begin{array}{l}\text { - Políticas urbanísticas. } \\
\text { - Políticas culturales. } \\
\text { - Políticas de activación } \\
\text { económica. } \\
\text { - Políticas sociales. }\end{array}$ & $\begin{array}{l}\text { - Planes de ordenación } \\
\text { urbanística. } \\
\text { - Declaraciones de bie- } \\
\text { nes de interés cultural. } \\
\text { - Planes especiales. }\end{array}$ & $\begin{array}{l}\text { - Ayuntamientos. } \\
\text { - Administración } \\
\text { cultural. } \\
\text { - Asociaciones } \\
\text { empresariales. } \\
\text { - Asociaciones } \\
\text { ciudadanas. }\end{array}$ \\
\hline
\end{tabular}

Fuente: elaboración propia.

los bienes puede limitarse a la faceta económica, y aun menos a la explotación turística. En ellos se impone el reto de la gestión integrada (Troitiño, 2011), y la ordenación del territorio cobra un protagonismo destacado (Alonso, 2014; Zárate, 2009).

Respecto al cómo de la gestión (los instrumentos) y el por quién y para quién (los actores), cada paisaje patrimonial, por su propio carácter y por sus propias circunstancias, se ve afectado por determinados programas públicos y tiene sus actores particulares. Requiere, en suma, un modelo de gestión particularizado que huya de la homogeneización antedicha. La tabla 4 resume, 
tomando España como ejemplo, las políticas, los instrumentos y los actores que afectan a cada paisaje en función de las dominantes paisajísticas básicas de su carácter (natural, rural y urbana), desde el convencimiento de que se trata de una sistematización meramente operativa, pues a menudo las dominantes se imbrican unas en otras.

Obviamente, determinadas políticas y planes se erigirán, en cada caso, en protagonistas de la gestión. Los planes generales de ordenación urbanística y la planificación estratégica se han revelado como instrumentos esenciales para la gestión patrimonial de áreas urbanas. Los paisajes patrimoniales de dominante rural no pueden gestionarse al margen de la política agraria comunitaria. Dicho de otra forma, la pretensión de preservar los paisajes del viñedo en La Rioja, El Priorat o Requena, por citar algunos ámbitos que aspiran a convertirse en paisajes culturales de la Unesco, no tiene demasiado sentido en tanto que la PAC continúe subvencionando los arranques de viñedos. Esa relación dominante del carácter paisajístico y de los instrumentos de gestión, aunque obvia, no debería soslayar la necesaria coordinación interadministrativa. Al igual que los paisajes y sus valores patrimoniales se incardinan unos en otros, las políticas también tendrían que hacerlo, lo que está lejos de constituir una realidad. Se verifica una creciente dispersión de programas, planes y actores que origina una gran confusión y provoca resultados no deseados. La gestión de los paisajes patrimoniales no precisa de nuevos planes o instrumentos, sino del conocimiento y la coordinación entre los ya existentes.

Otro aspecto relevante es el relacionado con el mantenimiento de la funcionalidad de los paisajes como garante de su autenticidad, y, a la postre, de su propia legitimidad patrimonial. Ello tampoco es una tarea fácil, particularmente en los casos en que los usos tradicionales (económicos y residenciales) han dejado de ser rentables y no pueden competir con los nuevos usos. Se impone la búsqueda de cauces imaginativos que infiltren el discurso patrimonial entre las políticas de mayor nivel (supranacionales) que son decisivas a estos propósitos. La incorporación de la dimensión ambiental entre los programas de la PAC podría servir de ejemplo. Dicho de otra forma, al igual que se subvencionan a través de ayudas los servicios ambientales proporcionados por la agricultura, también podría subvencionarse el papel de la agricultura como creadora de paisajes y de patrimonio cultural. Ello requiere una posición más activa y contundente de las asociaciones del patrimonio cultural que operan a nivel internacional, como Icomos.

La gestión patrimonial de bienes territoriales complejos, vividos y utilizados como los paisajes es un campo que no ha sido suficientemente explorado. La identificación inicial del patrimonio con bienes monumentales; con paisajes fósiles o anclados en el tiempo (yacimientos arqueológicos); con bienes que han perdido su funcionalidad original y emergen con otros usos (antiguas instalaciones industriales, complejos mineros), o con especies y enclaves de especial valor natural (caso del denominado patrimonio natural), implica un avance en la gestión de estos ámbitos, pero la mayor parte de las veces se asimila únicamente a la gestión turística (Troitiño y Troitiño, 2010). Mientras tanto, 
persisten importantes lagunas en torno al significado de la gestión en paisajes que siguen siendo funcionales y cuya autenticidad radica precisamente en el mantenimiento de las poblaciones (caso de los vecinos tradicionales en los paisajes urbanos) y de las actividades productivas (caso, aunque no solo, de los paisajes de la agricultura).

\section{Consideraciones finales}

Un nuevo paradigma patrimonial está en marcha, con nuevos tiempos, nuevos bienes y nuevos actores, y en consecuencia se precisan nuevos o renovados conceptos, métodos e instrumentos. Ello es particularmente patente en el caso de la geografía y del territorio. El desplazamiento del protagonismo patrimonial desde el objeto (la materialidad del bien) hasta el sujeto (la sociedad que crea y disfruta ese bien) ha tenido una amplia repercusión en disciplinas como la antropología. En geografía, ese camino ha sido poco desarrollado a pesar de la irrupción del territorio entre los bienes patrimoniales, primero como escenario y luego como actor (paisajes patrimoniales, itinerarios culturales, etcétera). Este articulo pretende reforzar esta vía de investigación que posee una doble dirección: la incorporación de la dimensión territorial al nuevo paradigma del patrimonio y, en sentido contrario, la impregnación de sus postulados en la geografía y en todo tipo de políticas territoriales.

Se ha hecho un esfuerzo conceptual y metodológico por reinterpretar el discurso sobre los procesos de patrimonialización (de raigambre básicamente antropológica) desde el punto de vista de la geografía y el territorio a través de los paisajes patrimoniales, todo ello con una perspectiva analítica y prospectiva. Se han tratado conceptos como los de vector patrimonial, densidad patrimonial, intensidad patrimonial, etcétera. Su aplicación empírica a paisajes muy diferentes en cuanto a dominantes de su carácter, tipos de vectores patrimoniales, escalas territoriales y perceptivas y rangos de reconocimiento (tomando como ejemplos la Sierra de Huelva y los paisajes urbanos malagueños) reafirman la virtualidad de la propuesta, que podría ser aplicada, introduciendo los requerimientos culturales específicos que se requiriesen, en paisajes de cualquier parte del planeta.

El concepto de vector patrimonial se ha manifestado muy útil para varios propósitos. Su definición como el atributo en torno al que se condensa la identificación social e institucional con los paisajes permite discernir qué es lo patrimonial dentro de ellos y dónde se sitúa. Igualmente, es un buen indicador del proceso de identificación de los paisajes patrimoniales, un asunto que se considera básico (patrimonialización implica selección) y sobre el que aún no se ha avanzado convenientemente. La concurrencia de agentes sociales e institucionales asignatarios de valores y de vectores patrimoniales condensadores de ese valor puede constituir, junto con otros criterios (la antigüedad, la grandiosidad, las connotaciones desde las miradas creativas, etcétera) una herramienta útil para la selección de los paisajes patrimoniales dentro del amplio universo de paisajes patrimonializables. No se resuelve en este artículo cuáles son las circunstancias por las que un determinado bien (un castillo, una ermita, un itinerario cultural) 
se convierte en vector patrimonial y genera paisajes culturales, pero sí se apunta al hecho de que son las percepciones sociales las que, con un proceso que no es ni lineal ni universal, terminan extrapolando al paisaje los valores culturales de los vectores patrimoniales entendidos de forma interrelacionada.

Los conceptos de densidad y de intensidad patrimonial, así como su concreción en expresiones o categorías susceptibles de ser cartografiados, permiten, a su vez, diferenciar distintos grados de patrimonialización dentro de los paisajes.

Todos estos conceptos y sus correspondientes traslaciones metodológicas ayudan a dirimir qué proteger, ordenar y gestionar de los paisajes. La preservación debe recaer en el vector y puede tener distintas modalidades (protección integral, compatible, preventiva, etcétera) en función de los indicadores de densidad e intensidad patrimonial, así como de otras circunstancias. Respecto al cómo de la gestión (la movilización de medios en las políticas patrimoniales), pesan más las incertidumbres que las propuestas. Aun así, la investigación hasta ahora realizada pone de manifiesto algunas deficiencias y apunta hacia algunas premisas básicas. Respecto a las primeras (las deficiencias), se ha comprobado que la instrumentación política del patrimonio tiende a homogeneizar lo diferente. Ello contradice una cualidad esencial de los paisajes (su carácter idiosincrático) y socava uno de los principios legitimadores del patrimonio (la excepcionalidad). Además de homogeneizadora, la gestión patrimonial trata a los bienes patrimoniales de manera autista y los desvincula de los territorios. Ello redunda en incoherencias y en mermas de su integridad, otro de los valores esenciales en la legitimación patrimonial. A su vez, el aprovechamiento turístico abusivo provoca banalizaciones y pérdidas de autenticidad, esto es, otros principios patrimoniales básicos.

Respecto a las premisas básicas para una gestión integral, cabe señalar las que siguen:

- Los paisajes patrimoniales son espacios vivos y funcionales y se resisten a la musealización. Sus vectores patrimoniales se dispersan por el territorio y no pueden comprimirse en paquetes turísticos.

- Los espacios complejos, donde la gente vive y trabaja, como los paisajes o la preservación de los valores patrimoniales, no pueden desvincularse de la ordenación y precisan del mantenimiento de su funcionalidad, aun en una perspectiva evolutiva de esta funcionalidad, como garantes de autenticidad patrimonial. Es necesario buscar nuevas fórmulas e instrumentos para preservar la vitalidad de los paisajes patrimoniales. A menudo, ello implica la incorporación de nuevas funcionalidades compatibles con su carácter. Los paisajes patrimoniales se hacen y se deshacen, pero debe velarse por el mantenimiento de sus valores.

- Urge recomponer la coordinación de las distintas políticas que sirven de instrumento para gestionar los paisajes, orientándola hacia la gestión integrada a través de propuestas innovadoras y valientes con recursos institucionales que ayuden a incorporar el discurso del patrimonio cultural entre las instituciones de mayor nivel. 
- La gestión de los paisajes patrimoniales no precisa de nuevos instrumentos o planes especiales, sino que necesita de la coordinación y la aplicación eficiente de los existentes. En ellos, se impone el entendimiento interadministrativo y la concertación socioinstitucional. Una tarea compleja pero necesaria.

\section{Referencias bibliográficas}

Agudo Torrico, Juan (1997). «Patrimonio etnológico: Problemática en torno a su definición y objetivos». Revista PH, 18, 97-108. Instituto Andaluz del Patrimonio Histórico.

Almirón, Analía; Bertoncello, Rodolfo y Troncos, Claudia Alejandra (2006). «Turismo, patrimonio y territorio: Una discusión de sus relaciones a partir de casos de Argentina». Estudios y Perspectivas en Turismo, 15 (2), 101-120.

Alonso, Pablo (2014). «La transición al pos-productivismo: Parques patrimoniales, parques culturales y ordenación territorial». Eure, 40 (119), 217-238.

ARNESE, Torn (2011). "Landscape as a sign: Semiotic and methodological issues in landscape studies». En: Roca, Zotsn, Claval, Paul y Agnew, John (eds.). Landscapes, identities and development. Farnham, UK: Ashgate, 363-376.

BeL, Carlos y Arranz, A. (2011). «El turismo y el desarrollo rural en los parques naturales: El caso del Parque Natural de Grazalema (Cádiz-Málaga)». Spanish Journal of Rural Development [en línea], II (2), 1-22. $<$ http://dx.doi.org/10.5261/2011.GEN2.01>

Beltrán, Oriol; Pascual, José J.; Vaccaro, Ismael (2008). Patrimonialización de la naturaleza: El marco social de las políticas ambientales. San Sebastián: Ankulegi.

Besse, Jean-Marc (2009). «Le paysage entre le politique et le vernaculaire». En: BEsSE, J.M. (ed.). Le goût du monde. Arles: Actes du Sud ENSP / Centre du Paysage.

CabeZAS, Juan Antonio (1956). Asturias: Biografia de una región. Madrid: Espasa-Calpe.

CAstillo, José (2009). «La dimensión territorial del patrimonio histórico: Caracterización y dimensiones». Castillo, José; Cejudo, Eugenio y Ortega, Antonio (eds.). Patrimonio histórico y desarrollo territorial. Sevilla: Universidad Internacional de Andalucía, 27-48.

Clark, Kate y Drury, Paul (2002). «Du monument au citoyen: Les fonctions du patrimoine culturel dans une Europe en évolution». Fuctions du patrimoine culturel dans une Europe en changement. Estrasburgo: Conseil de l'Europe, 119-124.

Countryside Agency and Scottish Natural Heritage (2002). Landscape Character Assessment: England and Scotland. Wetherby: Countryside Agency and Scottish Natural Heritage.

Cruz Pérez, Linarejos y Español-Echániz, Ignacio (2009). El paisaje: De la percepción a la gestión. Madrid: Liteam.

DíAz PARRA, Ibán (2015). «Viaje solo de ida: Gentrificación e intervención urbanística en Sevilla». Eure, 41, 145-166.

Feria ToRiBio, José María (2013). «El patrimonio territorial: Algunas aportaciones para su entendimiento y puesta en valor». e-rph, 12, 200-224.

FernándeZ Salinas, Víctor (2003). «El patrimonio como factor de desarrollo: Balance y perspectivas». Revista Ph, 42, 40-124. Instituto Andaluz del Patrimonio Histórico.

Fernández Salinas, Víctor y Silva Pérez, Rocío (2015). «Paisajes españoles susceptibles de ser incluidos en la Lista de Patrimonio Mundial de Unesco: Criterios 
para su identificación y selección». Boletín de la Asociación de Geógrafos Españoles, 68, 253-278.

Flys Junquera, Carmen y Sanz Alonso, Irene (2010). Paisajes culturales: Herencia y conservación. Alcalá de Henares: Universidad de Alcalá de Henares.

Gómez Mendoza, Josefina (1999). «Paisajes y espacios naturales protegidos en España». Boletín de la Institución Libre de Enseñanza, 34-35, 131-152.

- (2013). "Del patrimonio paisaje a los paisajes patrimonio». Documents d'Anàlisi Geogràfica, 59 (1), 5-20.

Hernández López, José de Jesús y Hernández López, Elizabeth Margarita (2015). «Proteger lo natural, desproteger lo social: Reflexiones de los impactos de la conservación de la naturaleza en México». Pasos: Revista de Turismo y Patrimonio Cultural, 13 (1), 73-88.

Hortelano Mínguez, Luis Alfonso (2011). «Turismo minero en territorios en desventaja geográfica de Castilla y León: Recuperación del patrimonio industrial y opciones de desarrollo local». Cuadernos de Turismo, 27, 531-539.

López Ontiveros, Antonio (2006). "Literatura, geografía y representación del paisaje». López Ontiveros, A.; Font, J. y Ortega Cantero, N. (coord.). Representaciones culturales del paisaje. Madrid: Universidad Autónoma de Madrid y Parque Nacional de Doñana, 13-40.

Maderuelo, Javier (dir.) (2012). Paisaje y patrimonio. Madrid: Adaba. Pensar el Paisaje, 5.

Martínez de Pisón, Eduardo (2012). «La montaña simbólica». Cuadernos Geográficos de la Universidad de Granada, 51, 8-17.

- (2013). «El paisaje: Circunstancia, patrimonio, saber y representación». En: Martínez de Pisón, Eduardo y Ortega, Nicolás (eds.). Paisaje y patrimonio. Madrid: FDS/UAM.

Mata Olmo, Rafael (2008). «El paisaje, patrimonio y recurso para el desarrollo territorial sostenible: Conocimiento y acción pública». Arbor, Ciencia, Pensamiento y Cultura, 729, 155-172.

Mata Olmo, Rafael; Meer Lecha-Marzo, Ángela de y Puente Hernández, Leonor de la (2012). «Sustainable development and maiking of territory and everyday landscapes as heritage-an experience in the Cantabrian mountains». En: FerIA Toribio, José María (ed.). Territorial Heritage and Development. Países Bajos: Taylor and Francis, 141-159.

Muñoz Flores, Juan Carlos (2008). «El turismo en los espacios naturales protegidos españoles, algo más que una moda reciente». Boletín de la Asociación de Geógrafos Españoles, 46, 291-304.

ObbelaAr, Derk Jan S. y Pedroli, Bas (2011). «Perspectives on Landscape Identity: A Conceptual Challenge». Landscape Research [en línea], 36, 321-339. <http://dx.doi.org/10.1080/01426397.2011.564860>

Olivera, Ana (2011). «Patrimonio inmaterial, recurso turístico y espíritu de los territorios». Cuadernos de Turismo, 27, 663-667.

Ortega Cantero, Nicolás (2009). «Paisaje e identidad: La visión de Castilla como paisaje nacional (1876-1936)». Boletín de la Asociación de Geógrafos Españoles, 51, 25-49.

Pérez Bustamante, Leonel y Parra Ponce, Claudia (2004). «Paisajes culturales: El parque patrimonial como instrumento de revalorización y revitalización del territorio». Teoría, 13, 9-24.

Prats, Llorenç (1997). Antropología y patrimonio. Barcelona: Ariel, 2004.

- (1998). "El concepto de patrimonio cultural». Politica y Sociedad: Revista de la Universidad Complutense. Facultad de Ciencias Políticas y Sociología, 27, 63-76. 
- (2012). «Patrimonio + Turismo = ¿Desarrollo?». Pasos: Revista de Turismo y Patrimonio Cultural, 2, 127-136.

Silva Pérez, Rocío y Fernández Salinas, Víctor (2015). «Los paisajes culturales de Unesco desde la perspectiva de América Latina y El Caribe». Revista Invi, 85, 181-214.

Silva Pérez, Rocío y Jover Báez, Jaime (en prensa). «Los paisajes patrimoniales de la Sierra de Huelva: Ensayo metodológico». Artículo aceptado para su publicación en la revista Estudios Geográficos.

Troitiño Vinuesa, Miguel Ángel (1998). «Turismo y desarrollo sostenible en las ciudades históricas con patrimonio arquitectónico-monumental». Estudios Turísticos, 137, 5-53.

- (2011). «Territorio, patrimonio y paisajes: Desafíos de una ordenación y gestión inteligente». Ciudad y Territorio, 169-170, 561-570.

Troitiño Vinuesa, Miguel Ángel y Troitiño Torralba, Libertad (2010). «Patrimonio y turismo: Una complementariedad necesaria en un contexto de uso responsable del patrimonio y la cualificación de la visita». Patrimonio Cultural de España, 3, 89-107.

Vázquez Varela, Carmen y Martín Gil, Fernando (2011). "Problemas de sostenibilidad del turismo rural en España». Anales de Geografía de la Universidad Complutense, 31, 171-194.

Zamora Acosta, Elías (2011). «Sobre patrimonio y desarrollo: Aproximación al concepto de patrimonio cultural y su utilización en los procesos de desarrollo territorial». Pasos: Revista de Turismo y Patrimonio Cultural, 9 (1), 101-113.

Zárate Martín, Manuel Antonio (2009). «Paisajes culturales urbanos españoles: La necesaria conciliación entre ordenación del territorio y urbanismo». Boletín de la Real Sociedad Geográfica, CXLV, 247-270.

- (2011). «Paisajes culturales urbanos, entre la protección y la destrucción». Boletín de la Asociación de Geógrafos Españoles, 57, 175-194. 